\title{
Article \\ Genome-Wide Identification and Analysis of the APETALA2 (AP2) Transcription Factor in Dendrobium officinale
}

\author{
Danqi Zeng ${ }^{1,2}$, Jaime A. Teixeira da Silva ${ }^{3}$, Mingze Zhang ${ }^{1,2}$, Zhenming Yu ${ }^{1}\left({ }^{10}\right.$, Can Si $^{1}$, Conghui Zhao ${ }^{1,2}$, \\ Guangyi Dai ${ }^{4}$, Chunmei He ${ }^{1, *}$ and Juan Duan ${ }^{1,5, *}$ \\ 1 Key Laboratory of South China Agricultural Plant Molecular Analysis and Genetic Improvement, Provincial \\ Key Laboratory of Applied Botany, South China Botanical Garden, Chinese Academy of Sciences, \\ Guangzhou 510650, China; zengdanqi20@scbg.ac.cn (D.Z.); zhangmingze@scbg.ac.cn (M.Z.); \\ zhenming311@scbg.ac.cn (Z.Y.); cans2013@163.com (C.S.); zhaoconghui@scbg.ac.cn (C.Z.) \\ 2 College of Life Sciences, University of the Chinese Academy of Sciences, No. 19A Yuquan Road, \\ Shijingshan District, Beijing 100049, China \\ 3 Independent Researcher, P. O. Box 7, Ikenobe 3011-2, Miki-cho, Kagawa-ken 761-0799, Japan; \\ jaimetex@yahoo.com \\ 4 Opening Public Laboratory, Chinese Academy of Sciences, Guangzhou 510650, China; daigy@scbg.ac.cn \\ 5 Center of Economic Botany, Core Botanical Gardens, Chinese Academy of Sciences, Guangzhou 510650, China \\ * Correspondence: hechunmei2012@scbg.ac.cn (C.H.); duanj@scib.ac.cn (J.D.); Tel.: +86-20-37252993 (J.D.); \\ Fax: +86-20-37252978 (J.D.)
}

check for updates

Citation: Zeng, D.; Teixeira da Silva, J.A.; Zhang, M.; Yu, Z.; Si, C.; Zhao,

C.; Dai, G.; He, C.; Duan, J.

Genome-Wide Identification and Analysis of the APETALA2 (AP2) Transcription Factor in Dendrobium officinale. Int. J. Mol. Sci. 2021, 22, 5221. https://doi.org/10.3390/ ijms22105221

Academic Editor: Lam-Son Phan Tran

Received: 12 April 2021

Accepted: 11 May 2021

Published: 14 May 2021

Publisher's Note: MDPI stays neutral with regard to jurisdictional claims in published maps and institutional affiliations.

Copyright: (C) 2021 by the authors Licensee MDPI, Basel, Switzerland. This article is an open access article distributed under the terms and conditions of the Creative Commons Attribution (CC BY) license (https:// creativecommons.org/licenses/by/ $4.0 /)$.

\begin{abstract}
The APETALA2 (AP2) transcription factors (TFs) play crucial roles in regulating development in plants. However, a comprehensive analysis of the AP2 family members in a valuable Chinese herbal orchid, Dendrobium officinale, or in other orchids, is limited. In this study, the 14 DoAP2 TFs that were identified from the D. officinale genome and named DoAP2-1 to DoAP2-14 were divided into three clades: euAP2, euANT, and basalANT. The promoters of all DoAP2 genes contained cis-regulatory elements related to plant development and also responsive to plant hormones and stress. qRT-PCR analysis showed the abundant expression of DoAP2-2, DoAP2-5, DoAP2-7, DoAP2-8 and DoAP2-12 genes in protocorm-like bodies (PLBs), while DoAP2-3, DoAP2-4, DoAP2-6, DoAP2-9, DoAP2-10 and DoAP2-11 expression was strong in plantlets. In addition, the expression of some $D o A P 2$ genes was down-regulated during flower development. These results suggest that DoAP2 genes may play roles in plant regeneration and flower development in D. officinale. Four DoAP2 genes (DoAP2-1 from euAP2, DoAP2-2 from euANT, and DoAP2-6 and DoAP2-11 from basal ANT) were selected for further analyses. The transcriptional activation of DoAP2-1, DoAP2-2, DoAP2-6 and DoAP2-11 proteins, which were localized in the nucleus of Arabidopsis thaliana mesophyll protoplasts, was further analyzed by a dual-luciferase reporter gene system in Nicotiana benthamiana leaves. Our data showed that pBD-DoAP2-1, pBD-DoAP2-2, pBD-DoAP2-6 and pBD-DoAP2-11 significantly repressed the expression of the LUC reporter compared with the negative control (pBD), suggesting that these DoAP2 proteins may act as transcriptional repressors in the nucleus of plant cells. Our findings on AP2 genes in D. officinale shed light on the function of AP2 genes in this orchid and other plant species.
\end{abstract}

Keywords: Dendrobium officinale; AP2 transcription factor; development; dual-luciferase reporter gene system; gene expression

\section{Introduction}

As relatively static organisms, biochemical and genetic mechanisms in plants tend to be sophisticated, including delicate networks involved in regulatory mechanisms that allow plants to adapt to varying environments and resist biotic and abiotic stresses. Transcription factors (TFs) are proteins that can bind to DNA in a sequence-specific manner to regulate transcription. The regulation of gene transcription by TFs is an extremely complicated process [1], and is vital to plant growth and environmental responses. APETALA2 
(AP2) belongs to the APETALA2/Ethylene Response Factor (AP2/ERF) superfamily [2,3], which participates in the regulation of various biological processes in plants, such as growth and development (flower development, somatic embryogenesis, meristem and leaf growth, etc.), hormones and stress responses [4-13].

Historically, the AP2/ERF superfamily has been divided into four separate families, namely the ERF, AP2, RAV and Soloist families $[3,10]$. The AP2 protein is exclusive to plants and contains two AP2 domains that have also been found in ancient plants such as gymnosperms, mosses, and Chlamydomonas, indicating that AP2 and EREBP (ethylene responsive element binding protein) families differentiated before Chlorophyta and Streptophyta lineages differentiated [14]. There are also similarities, including structures and conserved motifs, among the four families, suggesting that they have similar properties. For example, three A. thaliana AP2 genes (AtAP2-6, AtAP2-7 and AtAP2-11) are involved in the regulation of seed development [15].

TFs recognize target DNA sequences with different DBDs, thereby controlling the expression of target gene promoters at the transcriptional level [16]. The AP2 domain not only plays a key role in transcriptional regulation [7], but also serves as the basis for family classification. In particular, the AP2 family, which contains two AP2 domains and a small number of proteins with a single AP2 domain [2,3,10,17], was further subdivided into the euAP2 (which is characterized by the miR172 binding motif) and AINTEGUMENTA (ANT) (which is characterized by signature amino acid insertions in the AP2 domain) clades $[18,19]$ based on the amino acid sequences and nuclear localization of the two AP2 domains. Among them, the ANT clade was further divided into the basalANT and euANT clades. euANT proteins are defined by a long pre-domain region and four conserved motifs, which is the main difference between basalANT and euANT clades $[19,20]$. In total, based on differences in gene structure, plant AP2 proteins are divided into three subfamilies: euAP2, euANT and basalANT in the model plant Arabidopsis thaliana [20].

Early studies found that in A. thaliana, AP2 was a homeotic gene with a profound effect on floral organs that could determine the identity and fate of floral organs [21-24]. In rapeseed (Brassica napus), the AP2-like gene BABY BOOM regulates somatic embryogenesis [5]. In addition, the ANT clade is involved in the development of various plant organs, such as vegetative organs [25] and ovule development [26] in A. thaliana, fruit development in apple [27], berry size in grapevine [28], and many other examples. In addition, the rice $A P 2$-like gene $S N B$, which belongs to the euAP2 clade, regulates the development of grains, such as seed shattering [29], Eriobotrya japonica EjAP2-1 interacts with EjMYB to induce fruit lignification [30], while the maize (Zea mays) AP2 genes ids1 and sid1 regulate the initiation of corn flower meristems to determine the fate of meristem cells [31]. These studies demonstrate that the AP2 family is involved in the regulation of processes associated with plant development, such as flower development, embryonic development, meristem and leaf growth, among others.

Even though the AP2 family in plants has been extensively studied, AP2 family members in the medicinal (herbal) orchid, Dendrobium officinale, i.e., DoAP2s, have not been analyzed. The identification and analysis of DoAP2 family members will not only provide clues for revealing the function of AP2s in D. officinale, but also provide a theoretical basis for studying the functional conservation of AP2/ERF TFs, such as identifying new conserved protein domains and motifs, and enriching the functions of TF families in plants. In this study, $14 D o A P 2$ genes were identified from $D$. officinale. They were systematically analyzed, a phylogenetic tree was constructed, protein interactions were predicted, and promoter cis-acting elements were analyzed, including their subcellular localization and using a dual-luciferase reporter assay. Moreover, using quantitative real-time polymerase chain reaction (qRT-PCR), their expression patterns were analyzed at different developmental stages, including flower development, and in response to different stress treatments, to lay a theoretical foundation for further analyzing the functions of DoAP2s in D. officinale. 


\section{Results}

\subsection{Identification and Analysis of AP2 Gene Family in D. officinale}

A total of 14 genes (DoAP2-1 to DoAP2-14) annotated as AP2 TFs were identified from the $D$. officinale genome. All 14 AP2 proteins from $D$. officinale, 16 AP2 proteins from Oryza sativa, and $18 \mathrm{AP} 2$ proteins from $A$. thaliana were used to perform a phylogenetic analysis. The DoAP2 proteins were classified into three clades: euAP2, euANT, and basalANT (Figure 1A). The euANT clade contained the most (seven) AP2 proteins (DoAP2-2, DoAP2-4, DoAP2-5, DoAP2-7, DoAP2-9, DoAP2-13 and DoAP2-14), followed by the euAP2 clade with four members (DoAP2-1, DoAP2-3, DoAP2-8 and DoAP2-10), while only three AP2 proteins (DoAP2-6, DoAP2-11 and DoAP2-12) were found in the basalANT clade. The AP2 domain is responsible for DNA binding and protein complex formation of AP2 proteins [32]. Two AP2 domains were present in 13 of the 14 DoAP2 proteins, whereas DoAP2-14 only contained one AP2 domain (Figure 1B and Figure S1).

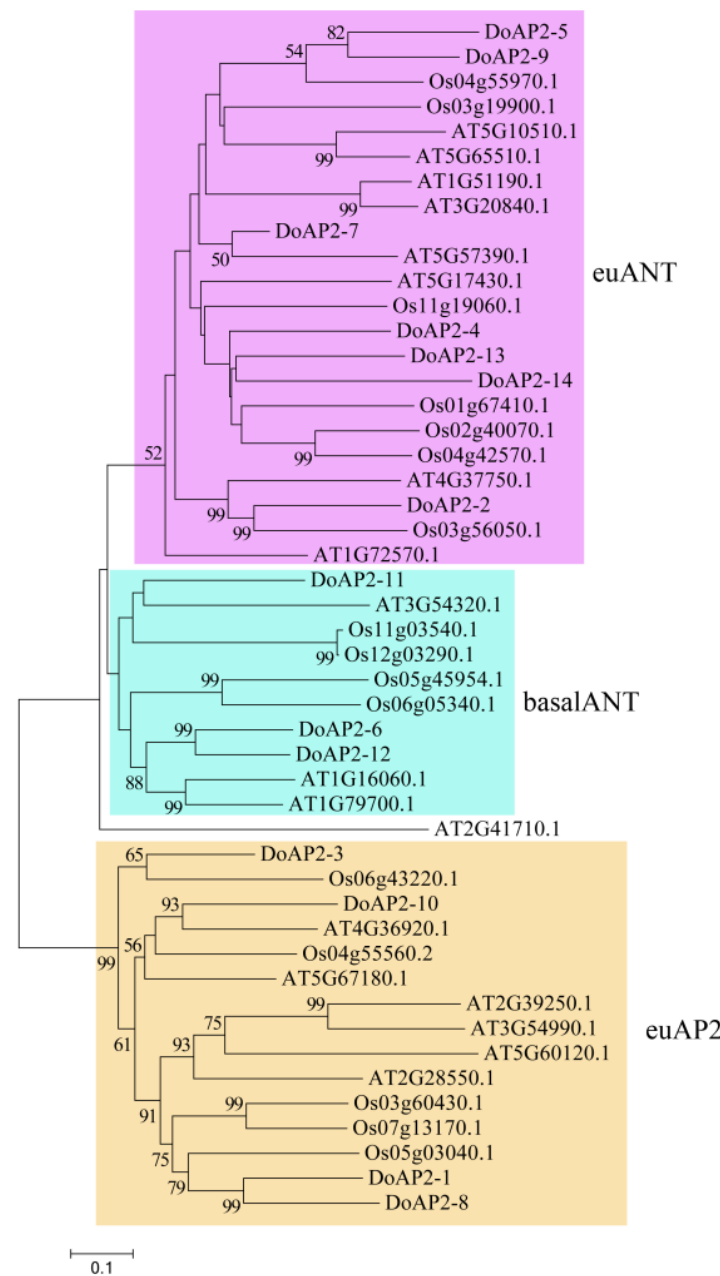

(A)

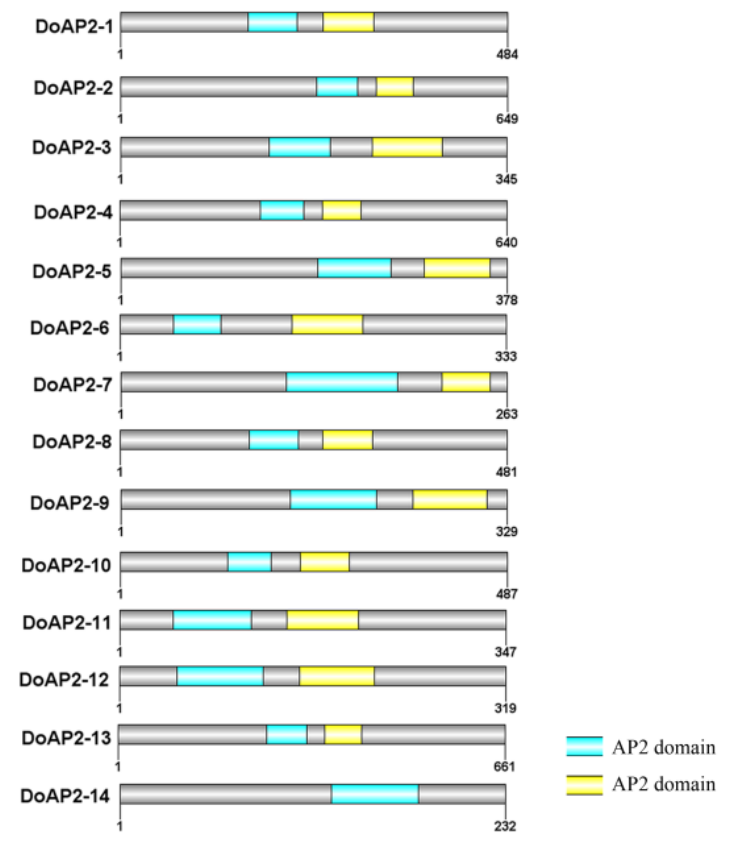

(B)

Figure 1. Phylogenetic analysis and conserved domain of the AP2 proteins from D. officinale, O. sativa and A. thaliana. (A) Phylogenetic tree of DoAP2 proteins. A total of 14 AP2 proteins from D. officinale, 16 from O. sativa and 18 from $A$. thaliana were aligned using ClustalX to generate a FASTA alignment file. The phylogenetic tree was constructed using the MEGA 7.0 program and the neighbor-joining (NJ) method with 1000 bootstrap replications based on the alignment file; (B) Conserved domain of DoAP2 proteins. The location and size of AP2 domains are shown by different colors. 


\subsection{Prediction of Protein-Protein Interaction Network of AP2 Proteins}

Protein-protein interactions play a role in transcriptional activation/repression and serve crucial functions in cellular regulation and biological processes in plants. Hence, we analyzed the protein-protein interaction network of the 14 DoAP2 proteins by STRING 11 and found that they were analogous to the interactions displayed by the corresponding A. thaliana orthologous proteins (Figure 2). These results show that several members of the DoAP2 family may have a certain connection to LEC1 and LEC2 of the LEC protein family, which is involved in embryonic development [33]. Interestingly, DoAP2-2, DoAP2-3, DoAP2-6, DoAP2-12, and DoAP2-14 were not linked to, nor did they interact with, any other DoAP2s based on the protein-protein interaction network of DoAP2s. Some DoAP2 proteins interacted with other DoAP2 proteins, such as DoAP2-4 and DoAP213 while others interacted with TFs involved in plant growth and development, such as DoAP2-1 and b-ZIP. These interactions suggest that DoAP2s play a broad role in plant growth and development.

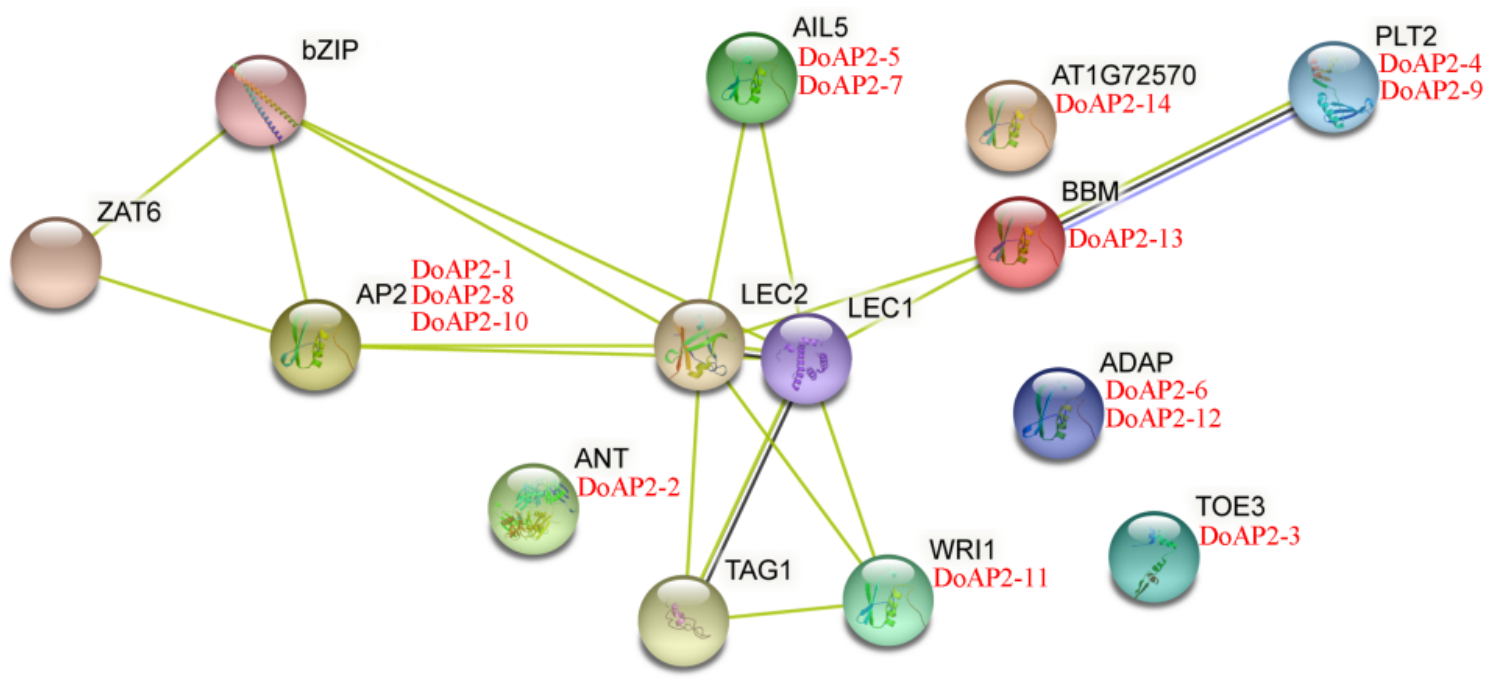

Figure 2. Protein-protein interaction network analysis of DoAP2 proteins using STRING 11. Cyan line represents data from curated databases, green lines indicate gene neighborhoods, and black lines indicate co-expression. Red text = DoAP2s; black text $=$ the proteins in A. thaliana.

\subsection{Analysis of Cis-Regulatory Elements in the Promoters of DoAP2 Genes}

$A P 2$ genes that are involved in plant growth and development are regulated by different factors. In order to investigate the cis-regulatory elements in the promoters of DoAP2 genes, we isolated the 2000-bp upstream section according to the $D$. officinale genome and analyzed the cis-regulatory elements using the PlantCARE web site. The cis-regulatory elements of the promoters of DoAP2 genes were related to growth and development (meristem expression and specific to the endosperm), plant hormones (auxin, abscisic acid, methyl jasmonate (MeJA), gibberellin, and salicylic acid) and stress (drought inducibility, low temperature responsiveness, anaerobic induction, and defense and stress responsiveness). As depicted in Figure 3, more than half of the DoAP2 genes harbored a total of seven meristem expression-responsive elements and eight endosperm specific-responsive elements, indicating that DoAP2 genes may play a vital role in meristem growth and embryonic development of $D$. officinale. In addition, an abundance of elements responsive to plant hormones was present in the promoters of all DoAP2 genes, demonstrating the response of these genes to these hormones. Interestingly, MeJA-responsive elements formed the largest group of elements among the promoters of DoAP2 genes, indicating that DoAP2 genes are MeJA-responsive genes (Figure 3). As a vital cellular regulator, MeJA plays a crucial role in mediating various developmental processes and defense responses against biotic and abiotic stresses [34]. Furthermore, except for DoAP2-10, the remaining 13 genes contained 
a total of 45 abiotic stress-responsive elements, not only suggesting that the expression of 13 DoAP2 genes was associated with these abiotic stresses, but also that they played a role in various stress regulatory networks. Collectively, these results indicate that AP2 family members participate in embryonic development, meristem growth and environmental stress regulation during the growth and development of $D$. officinale.

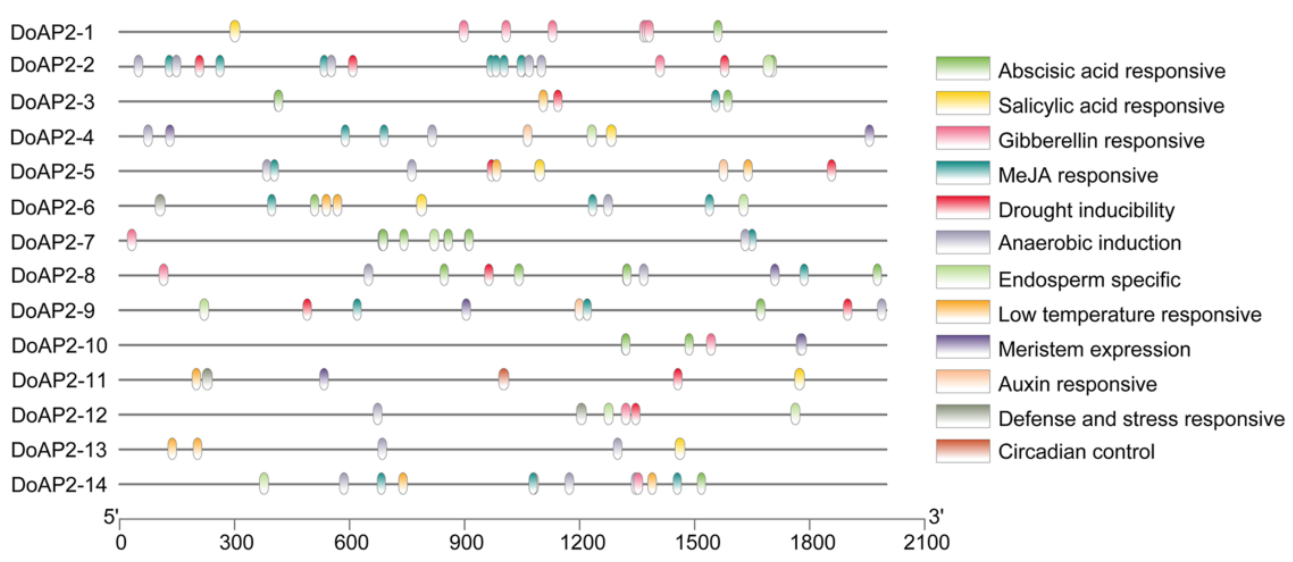

Figure 3. Prediction of cis-responsive elements in the 2-kbp upstream region of the initiation codon of 14 DoAP2 genes. Different colored boxes indicated different cis-responsive elements. MeJA, methyl jasmonate.

\subsection{Expression Analysis of DoAP2 Genes at Different Developmental Stages}

AP2 TFs are regarded as factors that are primarily responsible for the regulation of developmental programs [10]. Protocorm-like bodies (PLBs), which form during the in vitro culture of orchid plants, can proliferate or develop into a complete plant. We analyzed the changes in expression of DoAP2 genes during the development of PLBs to plantlets (PLBs, multiple shoots and plantlet). All DoAP2 genes were detected at all three developmental stages, except for DoAP2-4, which showed the highest expression in PLBs and the lowest expression in plantlets (Figure 4). The decrease in expression from PLBs to plantlets suggests that DoAP2-4 may play a role in PLB development. In addition, DoAP2-7 and DoAP2-8 were strongly detected in PLBs (Figure 4). DoAP2-3, DoAP2-4, DoAP2-6, DoAP2-9, DoAP2-10, and DoAP2-11, but especially DoAP-6, were abundant in plantlets (Figure 4). The expression of DoAP2-1 was not different among the three developmental stages. The DoAP2 genes displayed different expression patterns, even within the same clade. For example, in the euANT clade, DoAP2-2 and DoAP2-7 were highly expressed in PLBs while DoAP2-4 and DoAP2-9 were highly expressed in plantlets (Figure 4).

Flowers are important functional organs of plants. AP2 is involved in flower development [23]. For example, two genes, ANT and ANT-LIKE6, regulate $A$. thaliana floral growth and patterning [35]. We detected the expression of DoAP2 genes during three stages of D. officinale flower development, in small flower buds (FB1), medium flower buds (FB2), and fully bloomed flowers (FBF) (Figure 5). As shown in Figure 5, DoAP2-8 and DoAP2-10 exhibited a similar expression pattern, showing relatively high expression levels in FB1, decreasing as the flower developed further. The expression of DoAP2-3, which was in the same clade as DoAP2-8 and DoAP2-10, was up-regulated during flower development, and most expressed in FBF. A similar pattern was found in DoAP2-2, but a different expression pattern in DoAP2-4 and DoAP2-5, all from the euANT clade (Figure 5). Four out of seven euANT genes were abundant during FB1 (Figure 5). In particular, DoAP2-11 was specifically expressed in FBF, the expression of DoAP2-11 in FBF was about 193.56- and 2225.64-fold higher than in FB1 and FB2 while its expression level was much higher than that of other DoAP2 genes. These findings show the specificity of expression of different $D o A P 2$ genes in floral development. Moreover, seven DoAP2 genes (DoAP2-2, DoAP2-7, DoAP2-8, DoAP2-10, DoAP2-12, DoAP2-13, and DoAP2-14) had the highest expression in FB1 compared to FB2 and FBF, suggesting that they might play an essential role in the 
pre-flowering developmental state where differentiation is not yet complete. These results suggest that DoAP2 family members play a role in the development of $D$. officinale flowers.
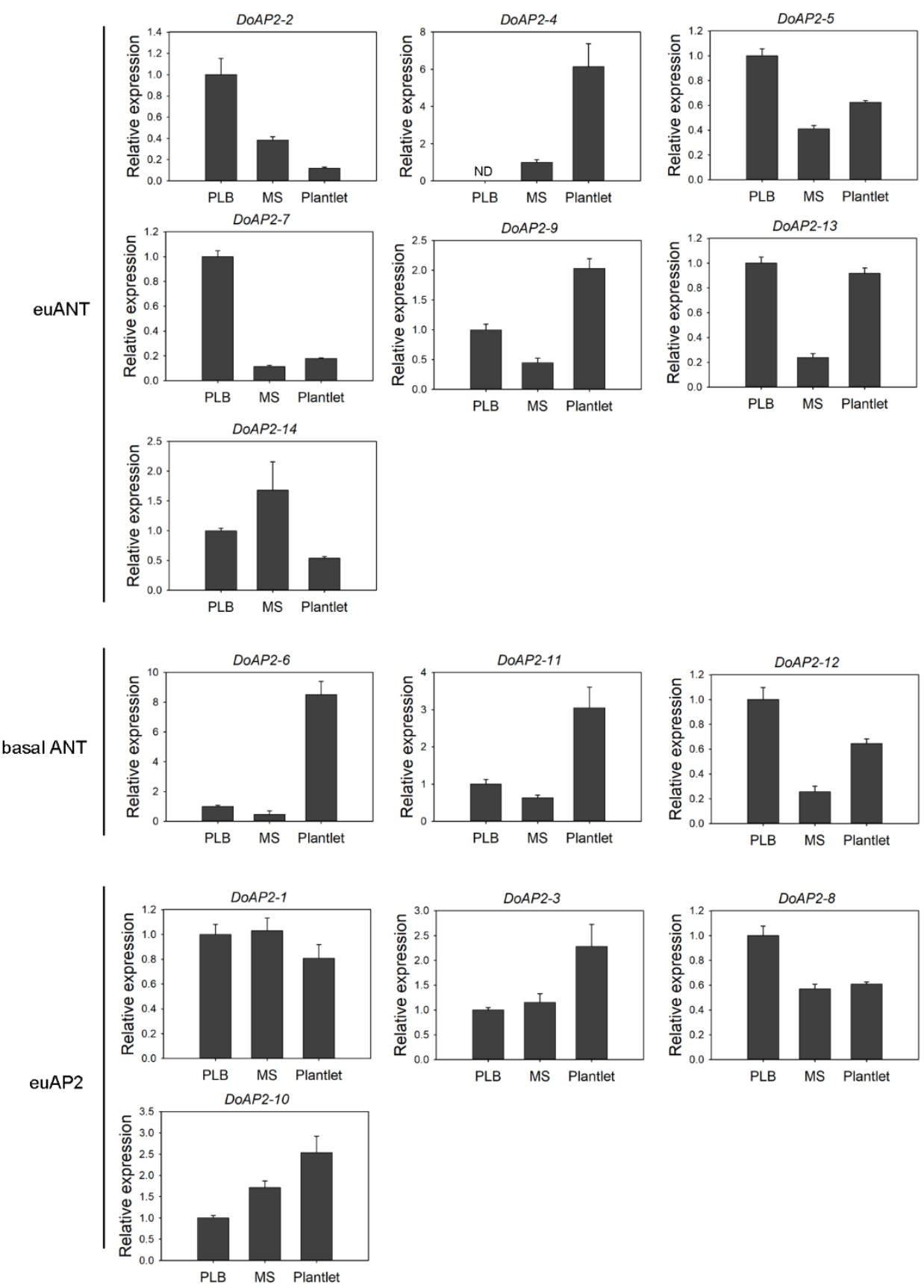

Figure 4. Expression analysis of $D o A P 2$ genes during plant regeneration from PLBs by qRT-PCR. PLB, protocorm-like bodies; MS, multiple shoots. Each data bar represents the mean \pm standard deviation (SD) of three biological replicates $(n=3)$. ND, not detected. 

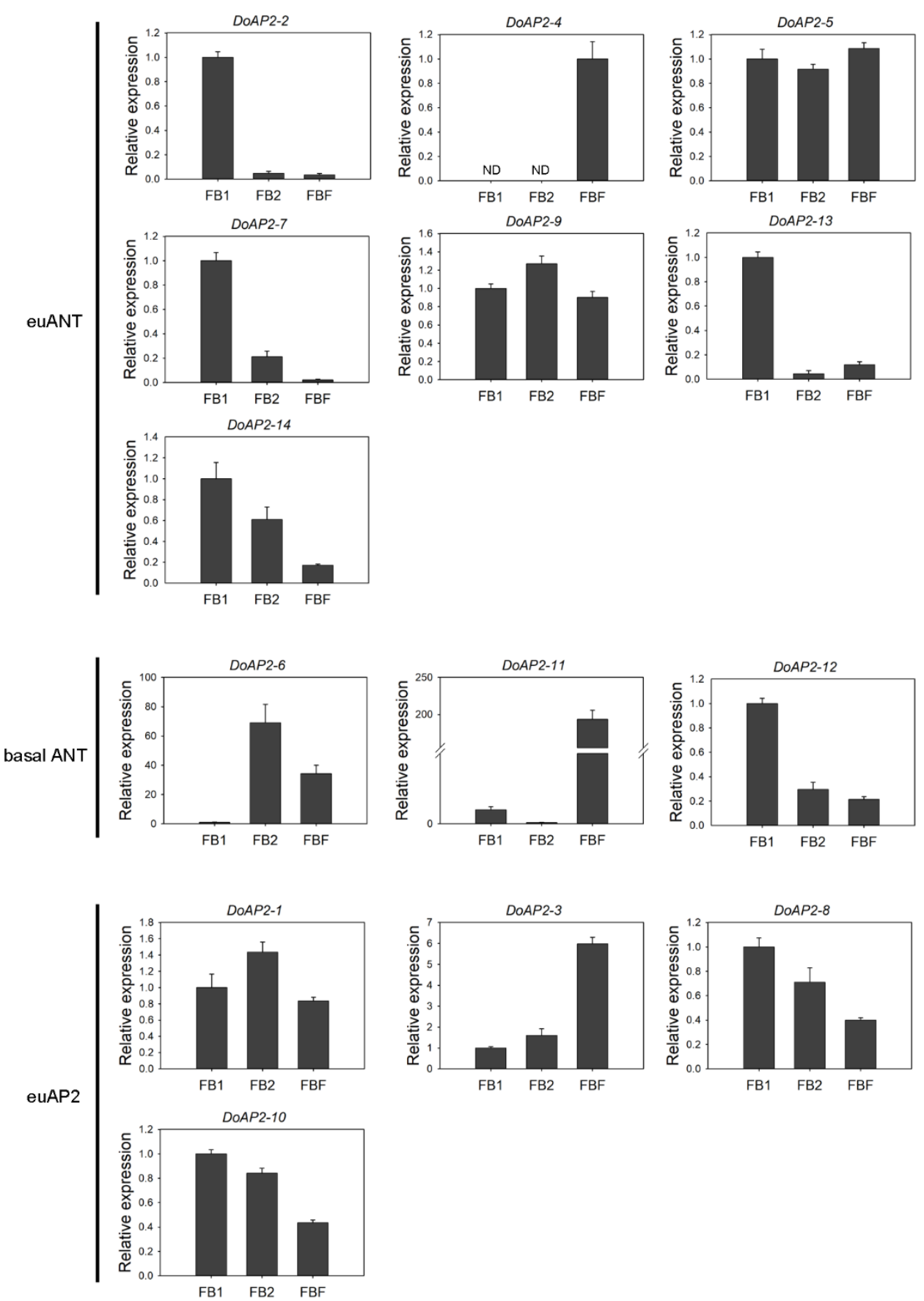

Figure 5. Expression analysis of DoAP2 genes during flower development by qRT-PCR. FB1, small flower buds (about $5 \mathrm{~mm}$ long); FB2, medium flower buds (about $10 \mathrm{~mm}$ long); FBF, fully bloomed flowers. Each data bar represents the mean \pm standard deviation (SD) of three biological replicates $(n=3)$. ND, not detected. 
The unique flower shape of orchids gives them high ornamental value [36]. We then analyzed the expression of DoAP2 genes in different floral tissues (sepal, petal, lip, and column) at the FBF stage (Figure S2). The expression of DoAP2-4 and DoAP2-13 was not detected in any of the four tissues of FBFs, and DoAP2-2, DoAP2-7, and DoAP2-14 were expressed only in the column and might be closely related to flower morphogenesis. Interestingly, the aforementioned genes that were specifically expressed, or not expressed, belong to the euANT clade. Remarkably, the remaining nine DoAP2 genes were expressed in different tissues of FBFs. Among them, DoAP2-1, DoAP2-3, and DoAP2-11 were more highly expressed in petals, and the expression trends of DoAP2-1 and DoAP2-3 of the same clade were consistent; DoAP2-6 was the most highly expressed in the column, the expression of the column was about 12.88-, 5.88- and 7.72-fold higher than in the sepal, petal and lip, respectively; the expression of DoAP2-5, DoAP2-9, DoAP2-10, and DoAP2-12 were all abundant and the variations were small among the four tissues of FBF. Based on these findings, DoAP2 genes had unique expression patterns, indicating that they probably played diverse roles in different $D$. officinale FBF tissues.

\subsection{Expression Analysis of DoAP2 Genes in Response to Abiotic Stresses}

$A P 2$ responds to abiotic stresses [37]. To further investigate the changes in expression of DoAP2 genes to different abiotic stress treatments (cold, PEG and $\mathrm{NaCl}$ ), we examined the expression levels of $14 D o A P 2$ genes under abiotic stress using qRT-PCR, while samples from untreated plantlets served as the control (Figure 6). According to their expression profiles, the expression of DoAP2-2, DoAP2-4, DoAP2-5, DoAP2-12, DoAP2-13, and DoAP214 were reduced to varying degrees. In addition, the differences in expression of DoAP2-11 in different treatments were slight, indicating that the above treatments had little effect on DoAP2-11. The expression of DoAP2-3 and DoAP2-7 in the $\mathrm{NaCl}$ treatment was about 3.49- and 2.56-fold higher than in the control, demonstrating that they played a role in the mechanism of response to stress in the face of adversity, especially high salt stress. The expression of DoAP2-9 in the cold treatment was more abundant than in the other three treatments. Compared to the control, the expression of at least one of the remaining $D o A P 2$ genes was up-regulated in response to these abiotic stress treatments. In particular, the expression of DoAP2-6 was 1.93-, 1.95- and 1.21-fold higher than the control in the cold, PEG and $\mathrm{NaCl}$ treatments, respectively, implying its potential importance in the adaptation of this orchid to adverse growth conditions experiencing abiotic stresses.

\subsection{Subcellular Localization of Selected DoAP2 Proteins}

To explore the localization of DoAP2 proteins, A. thaliana protoplasts were PEGmediated transformed with a transient expression vector containing YFP. According to the phylogenetic tree (Figure 1), AP2 proteins of D. officinale and A. thaliana were classified into three clades. We selected four representative genes, namely DoAP2-2 of the euANT clade, DoAP2-6 and DoAP2-11 of the basalANT clade, and DoAP2-1 of the euAP2 clade, for further analysis. Subcellular localization was observed using a Zeiss LSM 510 Meta confocal microscope. Yellow fluorescence signals of the positive control (empty YFP vector) were detected in the cytoplasm and plasma membrane (Figure S3). As expected, the yellow fluorescent signals of four YFP-DoAP2-fused proteins were localized in the nucleus (Figure 7), conforming to their transcriptional regulatory function in the nucleus. 

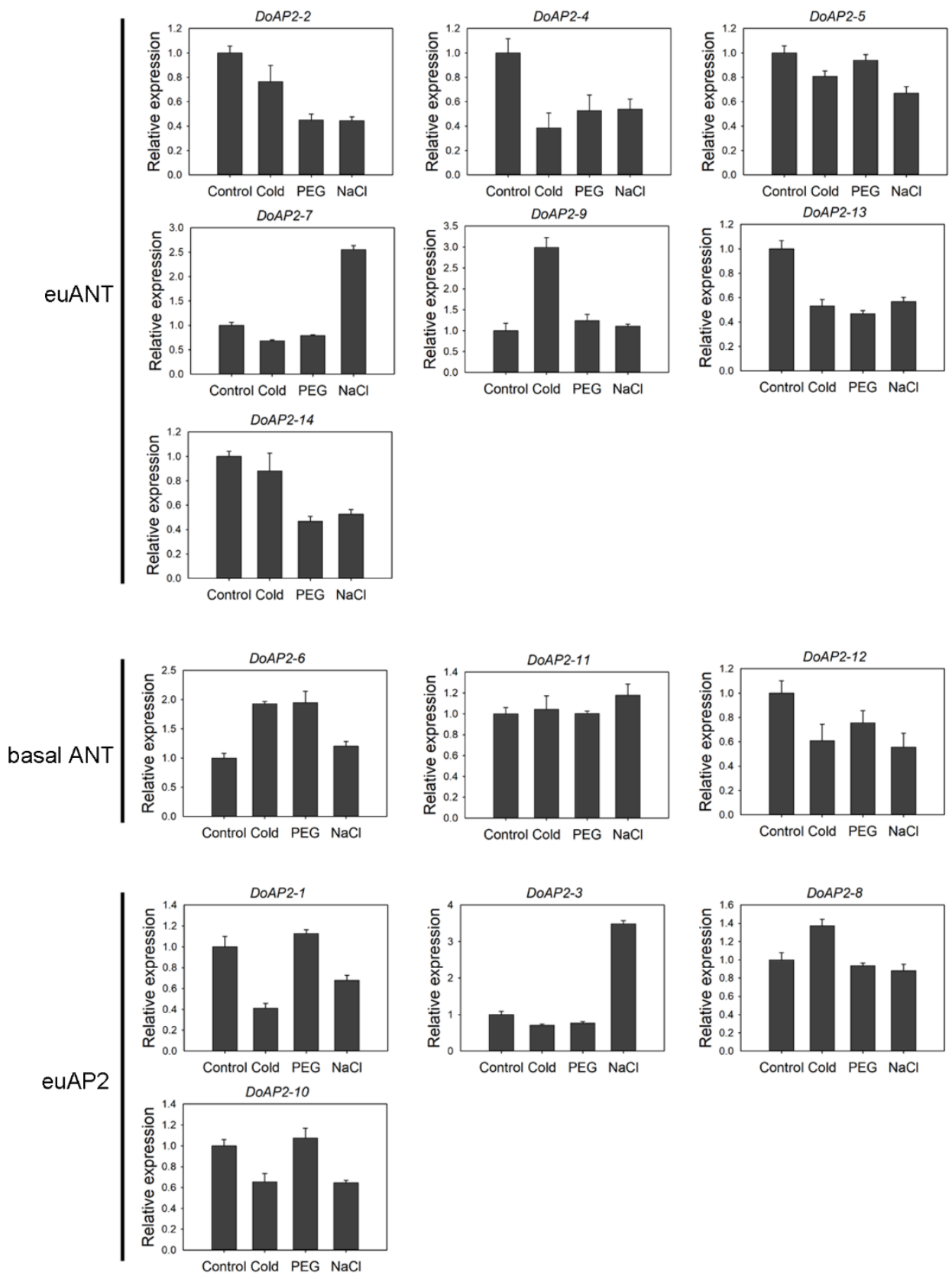

Figure 6. Expression analysis of DoAP2 genes in response to abiotic stresses (cold, PEG and $\mathrm{NaCl}$ ) by qRT-PCR. PEG treatment, 15\% polyethylene glycol (PEG)-6000; NaCl treatment, $250 \mathrm{mM} \mathrm{NaCl}$; cold treatment, $4{ }^{\circ} \mathrm{C}$. Each data bar represents the mean \pm standard deviation (SD) of three biological replicates $(n=3)$. 


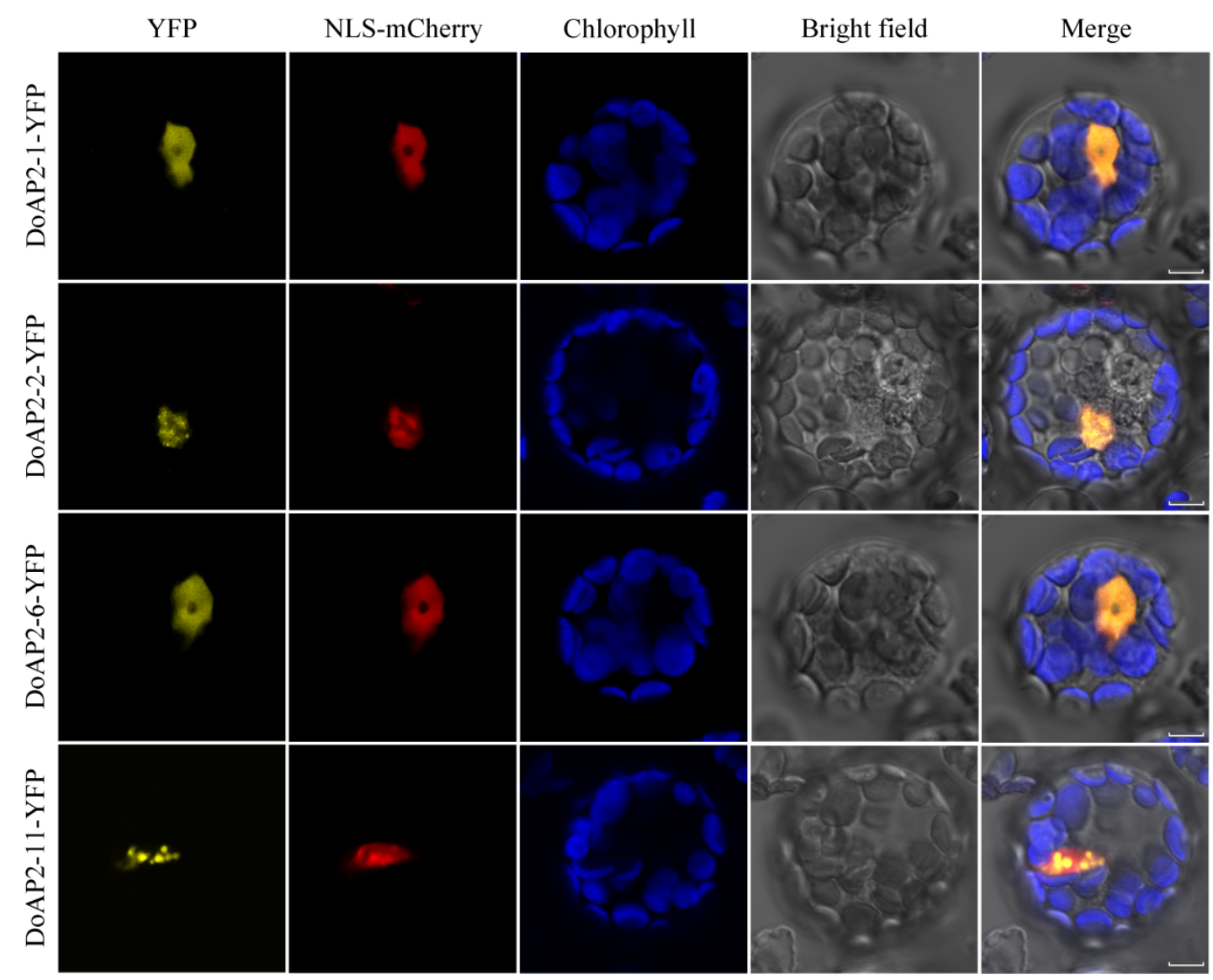

Figure 7. Subcellular localization of four DoAP2 proteins (DoAP2-1, DoAP2-2, DoAP2-6 and DoAP2-11) in A. thaliana protoplasts. Bars $=5 \mu \mathrm{m}$.

\subsection{Four DoAP2 Proteins Displayed Transcriptional Repression in Tobacco Leaves}

AP2 family members are considered to be TFs, and a defining feature of a TF is its transactivation activity [38]. Hence, we investigated the transcriptional activity of four DoAP2 genes (DoAP2-1, DoAP2-2, DoAP2-6 and DoAP2-11) using a dual-luciferase reporter gene system in tobacco (Nicotiana benthamiana) leaves. These representative genes are the same as those that were used for subcellular localization. The constructed vectors are shown in Figure 8A. We used vectors containing the CaMV35S-driven pBD and fusion protein vectors pBD-VP16, pBD-DoAP2s (DoAP2-1, DoAP2-2, DoAP2-6 and DoAP2-11) as the effector, and the CaMV35S-driven LUC and TATA cassette-driven REN as reporters. pBD-EMPTY and pBD-VP16 were used as negative and positive controls, respectively. In this system, the reporter vector was generated by fusing the firefly luciferase (LUC) gene after five GAL4 binding sites, and a renilla luciferase (REN) gene driven by a CaMV35S promoter in the reporter vector was used as the internal control (Figure 8A). The ORF of the four DoAP2 genes was cloned into the site of the pBD vector, which is after the GAL4 binding domain (Figure 8A). The ratio of the two luciferases (LUC and REN) was detected using a dual fluorescent reporter gene system assay (Figure $8 \mathrm{~B}$ ). The LUC/REN ratio of the positive control pBD-VP16 was 27-fold higher than the negative control pBD, while the LUC/REN ratio of the four $\mathrm{pBD}$-DoAP2 proteins was significantly lower than that of $\mathrm{pBD}$ (Figure 8B). These results show that DoAP2-1, DoAP2-2, DoAP2-6, and DoAP2-11 genes had transcriptional repression activity in tobacco plants, i.e., they are transcriptional repressors. 


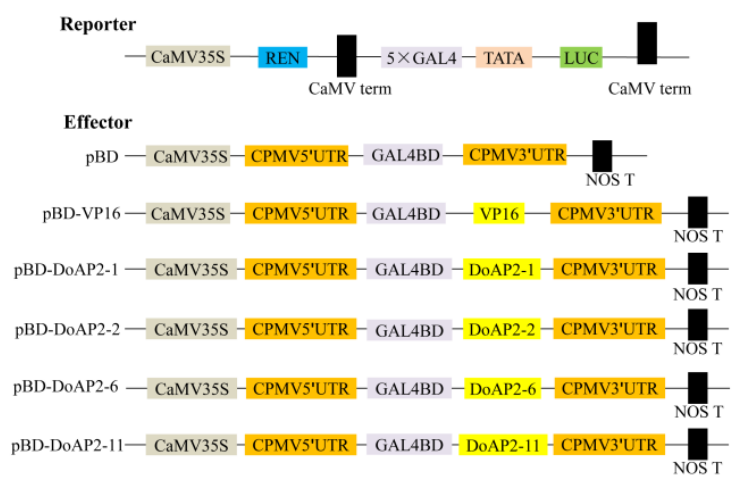

(A)

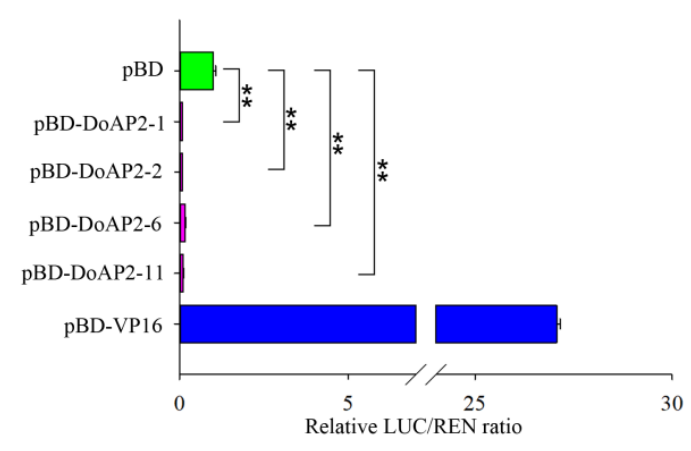

(B)

Figure 8. Transcriptional activity assay of DoAP2 genes in tobacco leaves. (A) Schematic presentation of the reporter and effector vectors; (B) Transcriptional repression ability of DoAP2 proteins in tobacco leaves. Double asterisks (**) indicate significant differences in two-treatment comparisons $(p<0.01)$ using Dunnett's test, compared with the negative control (pBD). Each value represents the means of six biological replicates.

\section{Discussion}

\subsection{Bioinformatics Analysis of DoAP2 TFs}

In this study, we identified 14 AP2 genes in the D. officinale genome. The AP2 family is a small TF family with fewer members in plants than the ERF TF family. For example, 18 AP2 genes were found in model plant Arabidopsis [3], 26 in Indica rice [39], and 62 in wheat [40]. The AP2 proteins from plants are divided into three subfamilies: euAP2, euANT and basalANT $[10,14,20,41]$. In this study, DoAP2 proteins were classified into euAP2, euANT and basalANT subfamilies, similar to other plants. All AP2 proteins contain two AP2 domains except for DoAP2-14, which has a single AP2 domain (Figure 1B and Figure S1). This is consistent with a prior finding that AP2 family members contain one or two AP2 domains [10].

A study of protein interactions can enrich the characteristics of TFs, such as localization, transcription activity, target specificity and function. Based on the STRING 11 tool, all protein-protein interaction networks of DoAP2 proteins were predicted. Interestingly, some DoAP2 proteins may interact with TFs involved in plant growth and development such as b-ZIP. Additionally, there are many reports on the interaction of proteins with members of the AP2/ERF superfamily. For example, rice OsERF3 interacted with WOX11 to regulate rice crown root development [42], AP2 TF HaDREB2 in sunflower (Helianthus annuus L.) interacted with another TF HaHSFA9 to regulate zygotic embryogenesis [43], and AtERF5 in A. thaliana interacted with AtERF6, AtERF8, SCL13 and other proteins to exert a wide range of regulatory effects, such as defense against phytopathogenic fungi [44,45]. The results of interaction protein prediction in this paper (Figure 2) provide a notion about the possible binding nature of DoAP2 proteins, although further verification is needed with yeast two hybrid, co-immunoprecipitation and bimolecular fluorescence complementation assays to determine the DoAP2 protein interaction network and its protein interaction under different conditions.

Increasing lines of evidence have shown that the AP2/ERF superfamily is mainly involved in development and abiotic stress responses $[5,7,8,13,46,47]$. In the present study, many growth and development, hormone and stress cis-acting elements were detected in the promoter regions of DoAP2 genes (Figure 3). In addition, cis-acting elements regulate the expression of stress-inducible genes, leading them to be referred to as molecular switches that regulate various biological processes [48]. The promoters of DoAP2 genes contain endosperm-specific cis-acting elements with expression in the meristem in response to growth and developmental processes, and that respond to multiple stress signals, which might regulate various biological processes. This is consistent with the basic functions of AP2 TFs $[37,49]$. Different DoAP2 TFs play a variety of roles that may be related to 
their specific and/or differential binding to different cis-acting elements or other proteins, suggesting their involvement in different regulatory processes [50-52].

\subsection{The AP2 TF Play Important Roles in Plant Regeneration and Flower Development}

An increasing number of studies provide evidence for the involvement of AP2 genes in plant regeneration and flower development.

In plant regeneration, AP2/ERF superfamily TFs promoted callus induction and proliferation, shoot differentiation, root differentiation and differentiation of somatic cells [53]. Several examples are provided next. Overexpression of the AP2 gene ZmBBM2 promoted callus induction and proliferation in maize [54]. In cacao (Theobroma cacao), overexpressed of the TCBBM gene induced embryo formation; moreover, the TCBBM gene can be used as an embryogenesis biomarker in cacao [11]. $\mathrm{HbAP2}-3$ and $\mathrm{HbAP2-7}$ genes are marker genes of somatic embryogenesis during callus proliferation in rubber tree (Hevea brasiliensis) [55]. An AP2/EREBP-type transcription activator NtCEF1 regulated gene expression in tobacco callus [56]. In rapeseed and A. thaliana, BBM, which shares similarities with the AP2/ERF superfamily of TFs, led to the differentiation of somatic cells, inducing embryonic development [5]. An AP2/ERF TF WOUND INDUCED DEDIFFERENTIATION1 (WIND1) promoted shoot regeneration in A. thaliana [57]. In A. thaliana, AP2/ERF TFs play an important role in root regeneration [58]. The AP2/ERF gene GmRAV1 regulated the regeneration of roots and adventitious buds in soybean [59]. D. officinale PLBs are considered to be somatic embryos that can proliferate and also differentiate into complete plants [60]. The induction, proliferation and regeneration of PLBs is an advantageous method for the large-scale production of D. officinale [61]. In addition, AP2 TFs specify the identity of floral organs and regulate the expression of genes related to flower development $[20-24,62,63]$. For example, $D$. officinale flowers contain three petalized sepals, two petals, one lip and one column [64], the unique floral patterning gives this orchid its ornamental value, it provides advantages to pollination, and promotes normal plant development [65]. In this study, there were five DoAP2 genes (DoAP2-2, DoAP2-5, DoAP2-7, DoAP2-8 and DoAP2-12) that showed abundant expression in PLBs from among the three development stages of D. officinale. In particular, it is important to emphasize that we found that DoAP2-2 and DoAP2-7 were specifically expressed in PLBs while DoAP2-2 was down-regulated during the development of $D$. officinale. Seven DoAP2 genes (DoAP2-2, DoAP2-7, DoAP2-8, DoAP2-10, DoAP2-12, DoAP2-13 and DoAP2-14) were strongly expressed in the early flower buds, and were down-regulated as flowers developed (Figure 5), suggesting that DoAP2 genes play a role in $D$. officinale flower development. Among them, the expression levels of DoAP2-2 and DoAP2-7 were highest in PLBs and FB1, and both strongly expressed in the column (Figure S2), indicating that DoAP2-2 and DoAP2-7 are highly specific genes that may play an important role in immature tissues of $D$. officinale. These findings imply that DoAP2 and DoAP2-7 genes are involved in regulating the maintenance of immature tissues and flower development, supporting the view that AP2 TFs have important functions in regulating plant growth and development. The expression levels of DoAP2-6 and DoAP2-11 of the same clade basal ANT were similar at different stages (Figure 4), and their expression continued to increase during development, peaking in plantlets and FBF. However, they also displayed some differences. Among the expression levels of different tissues in FBF, DoAP2-6 showed abundant expression in the column, while DoAP2-11 expression was abundant in sepals and petals. In D. officinale, DoAP2 genes have diverse roles in flowers, similar to the expression pattern of the NsAP2 gene in floral organs of water lily (Nymphaea sp. cv. 'Yellow Prince') [49]. Despite these similarities, flower development is a very complicated process, and $A P 2$ genes may be directly or indirectly involved in a certain regulatory role. Therefore, it is necessary to conduct more in-depth and detailed research on these genes. 


\subsection{DoAP2 Genes May Play a Role in Abiotic Stress Response}

The expression of DoAP2-6 increased to varying degrees, especially in response to cold stress and PEG treatment (Figure 6). The expression of DoAP2-11 also increased, but its amplitude was much lower than that of DoAP2-6 (Figure 6). This shows that the basal clade members DoAP2-6 and DoAP2-11 may have important regulatory effects under adverse abiotic stresses, allowing for a response to salt and drought stress during the growth and development of D. officinale plants. DoAP2-6 and DoAP2-11 contained a large number of stress-related cis-acting elements related to drought and low temperature (Figure 3), which may be closely related to their increased expression levels under different stress treatments (Figure 6), indicating that they are involved in the regulation of adverse abiotic stresses. Collectively, the above results suggest that genes with similar cis-acting elements among genes of the same clade may perform similar functions [66].

\subsection{The DoAP2 Proteins Are Localized in the Nucleus and Display Transcription Activity}

Nuclear localization is a key regulatory mechanism of TFs [67]. Our subcellular localization analysis of DoAP2 proteins indicated that, like many other AP2 and ERF TFs such as PsAP2 [68], OsDREBL [69] and GsERF71 [70], DoAP2-1, DoAP2-2, DoAP2-6 and DoAP2-11 were localized in the nucleus (Figure 7). These findings demonstrate that DoAP2 proteins have the basic characteristics of TFs, performing functions in the nucleus. However, since we selected representative genes of each clade from among the 14 DoAP2 TFs, this does not mean that all DoAP2 proteins have the above characteristics, and the related characteristics of the remaining proteins still needs additional research.

Based on their functions, TFs can be divided into either activators or repressors. Repressors play an important role in the regulation of gene expression by inhibiting the expression of certain genes by combining with DNA elements, transcription activators or promoter sequences [71], enabling plants to save energy under normal (non-adverse) conditions [72]. The expression of a repressor is also closely related to growth and development, and overexpression of repressors can lead to abnormal plant development $[73,74]$. However, compared with activators, there is less research on suppressors, especially in non-model plants. Previous studies showed that $A P 2$ genes can negatively regulate the expression of certain genes to achieve corresponding functions, and this has been well studied in A. thaliana. For example, early studies found that $A$. thaliana AP2 is a negative regulator of the AGAMOUS gene, both of which were involved in flower development, and the regulatory mechanism of their interaction established the expression pattern of floral homologous genes in A. thaliana to some extent [75]. An A. thaliana AP2 gene (At4g36920) negatively regulated the REPLUMLESS (RPL) gene that controls fruit dehiscence to achieve the function of controlling fruit development [62]. The $A P 2$ gene negatively regulates the size and number of embryonic cells, thus achieving the function of affecting seed mass and seed yield in A. thaliana [15,76]. Moreover, the AP2-like TF mutant of rice showed enlarged grains and increased grain weight [29], and AP2 genes also negatively regulated the formation of the abscission layer [77], thereby affecting the development of rice grains. In this study, we further tested the transcription activity of DoAP2 TFs using the dual-luciferase assay. As shown in Figure 8, DoAP2 genes had a strong repressive effect. This is likely to be related to the AP2/EREBP domain, which belongs to the DBD of a plant transcription repressor [32]. Such a repressor needs to bind to DNA to repress transcription [78]. In short, studies of repressors have important biological significance, and they can not only enrich our understanding of the negative regulatory role of plants in response to external environmental stresses, but also provide new theoretical guidance for genetic improvement of plant resistance to stresses in adverse growth conditions. Therefore, further in-depth studies on DoAP2 TFs will be of great significance for breeding and trait improvement. 


\section{Materials and Methods}

\subsection{Plant Material and Growth Conditions}

The D. officinale plants used in this study were grown and maintained in the South China Botanical Garden, Chinese Academy of Sciences, Guangzhou, China. The expression patterns of DoAP2 genes were performed on different $D$. officinale tissues (see below). The sampling method is also described below. PLBs, multiple shoots (MS, i.e., without roots) and plantlets (about $5 \mathrm{~cm}$ high) of D. officinale were grown on half-strength Murashige and Skoog (1/2MS) [79] medium supplemented with $20 \mathrm{~g} / \mathrm{L}$ sucrose, $6 \mathrm{~g} / \mathrm{L}$ agar and $1 \mathrm{~g} / \mathrm{L}$ activated carbon ( $\mathrm{pH}$ 5.4) in a growth chamber. We collected D. officinale material treated with PEG, $\mathrm{NaCl}$ and cold stress. Among them, concentrations were selected based on a relevant previous study [80]. First, D. officinale plants under normal growth conditions were cultured on $1 / 2 \mathrm{MS}$ with $0.1 \%$ activated carbon, $2 \%$ sucrose, and $0.6 \%$ agar medium ( $\mathrm{pH}$ 5.4). D. officinale plants were then separately exposed to one of several abiotic stresses (on the basis of the above growth conditions): 15\% polyethylene glycol (PEG)-6000 (SigmaAldrich, Shanghai, China; the PEG treatment), $250 \mathrm{mM} \mathrm{NaCl}$ (Guangzhou Chemical Reagent Factory, Guangzhou, China; the $\mathrm{NaCl}$ treatment) and $4{ }^{\circ} \mathrm{C}$ (the cold treatment). The culture conditions in controlled-climate chambers were: $26 \pm 1^{\circ} \mathrm{C}, 86.86 \mu \mathrm{mol} \cdot \mathrm{m}^{-2} \cdot \mathrm{s}^{-1}$, a 12 -h photoperiod, and about $60 \%$ relative humidity. In addition, MS and plantlets were derived from PLBs, as PLBs can grow into MS and plantlets after culture in the above medium. Each treatment was conducted as three replications and five D. officinale PLBs, MS and plantlets were used for each treatment. All samples were instantaneously frozen in liquid nitrogen for $15 \mathrm{~min}$ then stored at $-80^{\circ} \mathrm{C}$ for later use.

\subsection{Identification of DoAP2 Genes from the D. officinale Genome}

From the NCBI (https: / ftp.ncbi.nlm.nih.gov, accessed on 27 September 2020) genome database, we selected $D$. officinale and downloaded the $D$. officinale genome file. The AP2 protein sequences from $O$. sativa and A. thaliana were obtained from Plant Transcription Factor Database (http:/ / planttfdb.gao-lab.org/index.php, accessed on 9 October 2020). Genes were identified by a hidden Markov model (HMM) search based on the AP2 domain using the Pfam protein domain database (http:/ / pfam.xfam.org/, accessed on 10 October 2020). The HMM file was assessed by the HMMER3 software package under default parameters (http:/ /hmmer.janelia.org/, accessed on 10 October 2020). Subsequently, DoAP2 proteins were verified via a local HMM-based search program (E-value $\leq 1 \times 10^{-10}$ ). Furthermore, the identified sequences were confirmed to be AP2 proteins by annotation as an AP2 protein, either in the Uniprot database (https: / / www.uniprot.org/, accessed on 11 October 2020) or in the NCBI database. Retrieved AP2 protein sequences were compared with the A. thaliana AP2 protein sequences and a phylogenetic tree was constructed using the MEGA version 7 program [81]. Lastly, the remaining 14 proteins were considered to be $D$. officinale DoAP2 proteins.

\subsection{Bioinformatics Analysis of DoAP2 Proteins}

DNAMAN version 8.0 software (Lynnon Biosoft, Foster City, CA, USA) was used to generate multiple sequence alignments of full-length amino acid sequences of the DoAP2 proteins. In addition, we also used Clustal X 2.0 [82] to perform multiple alignments of DoAP2 proteins to further verify the results of sequence alignment. For the phylogenetic analysis, based on the alignment of AP2 proteins, we used MEGA version 7 [81] to perform phylogenetic and molecular evolutionary analyses of AP2 proteins. Initially, the amino acid sequences of the AP2 proteins from D. officinale and A. thaliana (FASTA format) were arrayed with Clustal X 2.0 [82], and the UniProt BLAST online website (http:/ / www.uniprot.org/ blast/, accessed on 11 October 2020) was used to calculate sequence identity based on the neighbor-joining method [83] with 1000 bootstrap replicates. Thus, a phylogenetic tree of $D$. officinale and A. thaliana AP2s was constructed. D. officinale AP2 proteins were categorized by their phylogenetic relationships with the corresponding A. thaliana AP2 proteins. Additionally, we used NCBI's conserved domain database (CDD) [84] to identify 
the conserved domains of DoAP2 proteins, and to calculate the conserved domain start sites and lengths. Finally, DOG2.0 software (http:/ / dog.biocuckoo.org/, accessed on 22 October 2020) was used to map the distribution of conserved domains.

We obtained the promoter sequences of DoAP2 genes (Table S1) from the D. officinale whole genome sequencing files. Subsequently, the upstream $2000 \mathrm{bp}$ sequence relative to the translation initiation codon (ATG) of the promoter of each DoAP2 gene was selected as the promoter region, and the PlantCare online software (http:/ / bioinformatics.psb.ugent. be/webtools/plantcare/html/, accessed on 19 November 2020) was used to predict the cis-acting elements in the promoters of DoAP2 genes. Finally, the prediction map of DoAP2 genes' promoters were drawn by TBtools [85].

Based on the association model of A. thaliana, the STRING 11 tool (https:/ / string-db. org, accessed on 2 December 2020) [86] was used to predict the protein-protein interaction network between DoAP2 proteins and other proteins.

\subsection{RNA Extraction, cDNA Synthesis and $q R T-P C R$}

The RNA extraction kit, RNAout2.0 reagent (Tiandz Inc., Beijing, China) was used to extract total RNA from the aforementioned D. officinale materials according to the operation manual. We used RNase-free DNase I (Takara Bio Inc., Kyoto, Japan) to purify RNA. After the extracted RNA was digested with DNase, $2 \mu \mathrm{L}$ was applied to agarose gel electrophoresis, and the integrity of the RNA was detected by the Clinx GenoSens gel documentation system (Clinx Science Instruments, Shanghai, China). Total RNA was reverse transcribed using the GoScript ${ }^{\mathrm{TM}}$ Reverse Transcription System (Promega, Madison, WI, USA) in accordance with the manufacturer's protocol, and $4 \mu \mathrm{g}$ of purified total RNA was used for reverse transcription. The reaction system was $20 \mu \mathrm{L}$ to synthesize first strand cDNA. The obtained cDNA was diluted in $\mathrm{ddH}_{2} \mathrm{O}$ to $1: 50$ and applied as a template for qRT-PCR analysis. The LightCycler 480 system (Roche, Basel, Switzerland) that uses the Aptamer $^{\mathrm{TM}}$ qPCR SYBR ${ }^{\circledR}$ Green Master Mix (Tianjin Novogene Bioinformatics Technology Co. Ltd., Tianjin, China) was used to perform qRT-PCR. Reaction conditions were: $95^{\circ} \mathrm{C}$ for $5 \mathrm{~min}$, and 40 subsequent cycles of $95^{\circ} \mathrm{C}$ for $10 \mathrm{~s}$ and $60^{\circ} \mathrm{C}$ for $1 \mathrm{~min}$. D. officinale ACTIN (NCBI accession number: JX294908) was used as the internal reference gene [87] to standardize cDNA concentration. Relative gene expression was calculated using the $2^{-\triangle \Delta C T}$ method [88]. Supplementary Table S2 lists the specific primer sequences for the DoAP2 genes. Three independent biological replicates were performed for each sample.

\subsection{Subcellular Localization Analysis}

The transient gene expression system that uses A. thaliana mesophyll protoplasts is an advantageous tool, and is often used for subcellular localization. First, we inserted the entire coding sequence of the four DoAP2 genes (DoAP2-1, DoAP2-2, DoAP2-6 and DoAP211) without stop codons into the EcoRI site of the pSAT6-EYFP-N1 vector [89]. In addition, this study used an additional method [90] to isolate protoplasts from $A$. thaliana leaves at the 4-weeks-old stage. Since TFs are generally located in the nucleus, for further verification, the recombinant protein was combined with the NLS location marker to transform A. thaliana mesophyll protoplasts using a PEG-mediated method [90]. After incubation for $12-18 \mathrm{~h}$ in the dark, a Leica TCS SP8 STED $3 \times$ microscope (Wetzlar, Hesse, Germany) was used to excite the YFP fluorescence signal at $514 \mathrm{~nm}$ to observe the yellow fluorescence signal of $A$. thaliana mesophyll protoplasts. The primers used to construct the four YFPDoAP2 fused proteins are listed in Supplementary Table S3.

\subsection{Dual-Luciferase Reporter (DLR) Assay}

The DLR assay, which was used to investigate the transcriptional activation of TFs, was performed according to a previous report [91]. Briefly, the coding sequences of DoAP2 (DoAP2-1, DoAP2-2, DoAP2-6 and DoAP2-11) genes without the stop codon were inserted into the constructed $\mathrm{pBD}$ vector driven by the $35 \mathrm{~S}$ promoter as effector, and the doublereporter vector as reporter, which includes a GAL4-LUC and an internal control REN driven 
by the $35 \mathrm{~S}$ promoter. The effector and reporter were genetically transformed into tobacco (about 5-6 weeks, young non-flowering plants) leaves using Agrobacterium tumefaciens strain GV3101 (Weidi, Shanghai, China) and tobacco plants were cultured in the dark for 3 days at $25^{\circ} \mathrm{C}$. Finally, according to the manufacturer's instructions, the activities ratio of the two luciferases (LUC and REN) was carried out using the DLR assay (Promega Corp., Madison, WI, USA) and measured using a GloMax 20/20 luminometer (Promega Corp.). The results were calculated as the ratio of LUC to REN. Six independent biological replicates were performed. At least six transient assay measurements were performed for each assay. The primers used to construct the four pBD-DoAP2 fusion constructs are listed in Supplementary Table S4.

\subsection{Statistical Analysis}

In figures, data have been plotted as means \pm standard deviation (SD). Analysis of variance (ANOVA) followed by the Dunnet test was used to determine significant differences at $p<0.05$ and $p<0.01$. Analyses were conducted with SPSS v. 22.0 software (IBM) for Windows (IBM Corp., Armonk, NY, USA).

\section{Conclusions}

We identified 14 DoAP2 TFs from a precious Chinese herbal medicinal orchid, D. officinale. We analyzed the expression of DoAP2 genes in different tissues of D. officinale and provided evidence for the specific expression and important regulatory roles at different developmental stages. Promoter analysis of DoAP2 genes showed that they contained a large number of cis-acting elements related to development and abiotic stress, supporting the diversity of their regulatory functions. Results of the protein interaction prediction helped to find putative functions for the DoAP2 TFs, providing a basis for further analysis and verification. Moreover, qRT-PCR analysis showed that DoAP2 genes are involved in regulating many biological processes such as floral development, embryonic development and adversity to stress, thus play a variety of roles in D. officinale. Importantly, use of CLSM to observe the subcellular localization of DoAP2-1, DoAP2-2, DoAP2-6, and DoAP2-11 allowed for the verification that all were localized in the nucleus. Furthermore, the DLR assay demonstrated that DoAP2-1, DoAP2-2, DoAP2-6, and DoAP2-11 proteins displayed strong transcription inhibitory activity in Nicotiana benthamiana, indicating that they are transcriptional repressors that inhibit expression. Overall, our study shows not only that DoAP2 TFs have transcriptional inhibitory activity, but also that they were mainly involved in regulating different growth and development stages of $D$. officinale, especially flower development. Our results have relevance to genetically modified resistant breeding since DoAP2 genes were expressed in PLBs, flowers, and plantlets, and were involved in biological processes such as stress response.

Supplementary Materials: The following are available online at https:/ /www.mdpi.com/article/10 $.3390 /$ ijms22105221/s1, Figure S1. Multiple sequence alignment of all DoAP2 proteins using ClustalX 2.1, Figure S2. Expression analysis of DoAP2 genes in different tissues of FBF by qRT-PCR, Figure S3. Subcellular localization of positive control (empty YFP vector) in A. thaliana protoplasts, Table S1. Promoter sequences of DoAP2 genes, Table S2. Primers used for qRT-PCR, Table S3. Primers used for subcellular localization analysis, Table S4. Primers used for the dual-luciferase reporter gene system.

Author Contributions: Conceptualization, J.D. and C.H.; methodology, D.Z. and C.H.; software, D.Z., C.H. and G.D.; validation, D.Z., M.Z., Z.Y., C.S. and C.Z.; formal analysis, D.Z., C.H. and J.A.T.d.S.; investigation, D.Z.; resources, J.D.; data curation, D.Z. and C.H.; writing—original draft preparation, D.Z., C.H. and J.A.T.d.S.; writing-review and editing, D.Z., J.A.T.d.S. and C.H.; visualization, D.Z. and C.H.; supervision, J.D.; and project administration, J.D. All authors have read and agreed to the published version of the manuscript.

Funding: This research was supported by the Foundation of the Key Laboratory of South China Agricultural Plant Molecular Analysis and Genetic Improvement, South China Botanical Garden, 
Chinese Academy of Sciences, grant number KF202008, and the Natural Science Foundation of Guangdong, China, grant number 2021A1515012170.

Institutional Review Board Statement: Not applicable.

Informed Consent Statement: Not applicable.

Data Availability Statement: Not applicable.

Conflicts of Interest: The authors declare no conflict of interest.

$\begin{array}{ll}\text { Abbreviations } \\ \text { 1/2MS } & \text { half-strength Murashige and Skoog (1962) medium } \\ \text { AD } & \text { transcriptional activation domain } \\ \text { AP2 } & \text { APETALA2 } \\ \text { AP2/ERF } & \text { APETALA2/Ethylene Response Factor } \\ \text { BD } & \text { DNA-binding domain } \\ \text { CDD } & \text { conserved domain database } \\ \text { Co } & \text { column } \\ \text { DBD } & \text { DNA binding domain } \\ \text { EREB } & \text { ethylene response element binding factor } \\ \text { FB1 } & \text { small flower bud } \\ \text { FB2 } & \text { medium flower bud } \\ \text { FBF } & \text { fully bloomed flower } \\ \text { HMM } & \text { Hidden Markov mode } \\ \text { Li } & \text { lip } \\ \text { LUC } & \text { firefly luciferase } \\ \text { MEGA } & \text { Molecular Evolutionary Genetics Analysis } \\ \text { MS } & \text { multiple shoots } \\ \text { PEG } & \text { polyethylene glycol } \\ \text { PLB } & \text { protocorm-like body } \\ \text { Pe } & \text { petal } \\ \text { qRT-PCR } & \text { quantificational real-time polymerase chain reaction } \\ \text { REN } & \text { renilla luciferase } \\ \text { Se } & \text { sepal } \\ \text { TF } & \text { transcription factor } \\ \text { YFP } & \text { yellow fluorescent protein } \\ & \end{array}$

\section{References}

1. Lambert, S.A.; Jolma, A.; Campitelli, L.F.; Das, P.K.; Weirauch, M.T. The human transcription factors. Cell 2018, 172, 650-665. [CrossRef] [PubMed]

2. Sakuma, Y.; Liu, Q.; Dubouzet, J.G.; Abe, H.; Shinozaki, K.; Yamaguchi-Shinozaki, K. DNA-binding specificity of the ERF/AP2 domain of Arabidopsis DREBs, transcription factors involved in dehydration- and cold-inducible gene expression. Biochem. Biophys. Res. Commun. 2002, 290, 998-1009. [CrossRef]

3. Nakano, T.; Suzuki, K.; Fujimura, T.; Shinshi, H. Genome-wide analysis of the ERF gene family in Arabidopsis and rice. Plant Physiol. 2006, 140, 411-432. [CrossRef] [PubMed]

4. Elliott, R.C.; Betzner, A.S.; Huttner, E.; Oakes, M.P.; Tucker, W.; Gerentes, D.; Smyth, P. AINTEGUMENTA, an APETALA2-like gene of Arabidopsis with pleiotropic roles in ovule development and floral organ growth. Plant Cell 1996, 8, 155-168. [CrossRef]

5. Boutilier, K.; Offringa, R.; Sharma, V.K.; Kieft, H.; Campagne, M.M.V.L. Ectopic expression of BABY BOOM triggers a conversion from vegetative to embryonic growth. Plant Cell 2002, 14, 1737-1749. [CrossRef]

6. Graaff, E. A new role for the Arabidopsis AP2 transcription factor, LEAFY PETIOLE, in gibberellin-induced germination is revealed by the misexpression of a homologous gene, SOB2/DRN-LIKE. Plant Cell 2006, 18, 29-39. [CrossRef]

7. Mizoi, J.; Shinozaki, K.; Yamaguchi-Shinozaki, K. AP2/ERF family transcription factors in plant abiotic stress responses. BBA Gene Regul. Mech. 2012, 1819, 86-96. [CrossRef] [PubMed]

8. Koichiro, A.; Tokunori, H.; Kanna, S.I.; Miyako, U.T.; Hidemi, K.; Makoto, M. A novel AP2-type transcription factor, SMALL ORGAN SIZE1, controls organ size downstream of an auxin signaling pathway. Plant Cell Physiol. 2014, 897-912. [CrossRef]

9. Chuck, G.; Meeley, R.B.; Hake, S. The control of maize spikelet meristem fate by the APETALA2-like gene indeterminate spikelet1. Genes Dev. 1998, 12, 1145. [CrossRef] [PubMed] 
10. Licausi, F.; Ohme-Takagi, M.; Perata, P. APETALA/Ethylene Responsive Factor (AP2/ERF) transcription factors: Mediators of stress responses and developmental programs. New Phytol. 2013, 199, 639-649. [CrossRef] [PubMed]

11. Florez, S.L.; Erwin, R.L.; Maximova, S.N.; Guiltinan, M.J.; Curtis, W.R. Enhanced somatic embryogenesis in Theobroma cacao using the homologous BABY BOOM transcription factor. BMC Plant Biol. 2015, 15, 1-12. [CrossRef] [PubMed]

12. Lowe, K.; Wu, E.; Wang, N.; Hoerster, G.; Hastings, C.; Cho, M.J.; Scelonge, C.; Lenderts, B.; Chamberlin, M.; Cushatt, J. Morphogenic regulators Baby boom and Wuschel improve monocot transformation. Plant Cell 2016, 28, 1998-2015. [CrossRef]

13. Chandler, J.W. Class VIIIb APETALA2 ethylene response factors in plant development. Trends Plant Sci. 2017, $23,151-162$. [CrossRef]

14. Shigyo, M.; Hasebe, M.; Ito, M. Molecular evolution of the AP2 subfamily. Gene 2006, 366, 256-265. [CrossRef] [PubMed]

15. Ohto, M.A.; Fischer, R.L.; Goldberg, R.B.; Nakamura, K.; Harada, J.J. Control of seed mass by APETALA2. Proc. Natl. Acad. Sci. USA 2005, 102, 3123-3128. [CrossRef] [PubMed]

16. Yamasaki, K.; Kigawa, T.; Seki, M.; Shinozaki, K.; Yokoyama, S. DNA-binding domains of plant-specific transcription factors: Structure, function, and evolution. Trends Plant Sci. 2013, 18, 267-276. [CrossRef]

17. Zhuang, J.; Cai, B.; Peng, R.-H.; Zhu, B.; Jin, X.-F.; Xue, Y.; Gao, F.; Fu, X.-Y.; Tian, Y.-S.; Zhao, W.; et al. Genome-wide analysis of the AP2/ERF gene family in Populus trichocarpa. Biochem. Biophys. Res. Commun. 2008, 371, 468-474. [CrossRef] [PubMed]

18. Shigyo, M.; Ito, M. Analysis of gymnosperm two-AP2-domain-containing genes. Dev. Genes Evol. 2004, 214, 105-114. [CrossRef] [PubMed]

19. Horstman, A.; Willemsen, V.; Boutilier, K.; Heidstra, R. AINTEGUMENTA-LIKE proteins: Hubs in a plethora of networks. Trends Plant Sci. 2014, 19, 146-157. [CrossRef] [PubMed]

20. Kim, S.; Soltis, P.S.; Wall, K.; Soltis, D.E. Phylogeny and domain Evolution in the APETALA2-like gene family. Mol. Biol. Evol. 2006, 23, 107-120. [CrossRef] [PubMed]

21. Komaki, M.K.; Okada, K.; Nishino, E.; Shimura, Y. Isolation and characterization of novel mutants of Arabidopsis thaliana defective in flower development. Development 1988, 104, 1536-1546. [CrossRef]

22. Bowman, J.L.; Smyth, D.R.; Meyerowitz, E.M. Genes directing flower development in Arabidopsis. Plant Cell Online 1989, 1, 37-52. [CrossRef]

23. Kunst, L.; Klenz, J.E.; Haughn, M. AP2 gene determines the identity of perianth organs in flowers of Arabidopsis thaliana. Plant Cell 1989, 1, 1195-1208. [CrossRef]

24. Bowman, J.L.; Smyth, D.R.; Meyerowitz, E.M. Genetic interactions among floral homeotic genes of Arabidopsis. Development 1991, 112, 1-20. [CrossRef]

25. Krizek, B.A. AINTEGUMENTA-LIKE genes have partly overlapping functions with AINTEGUMENTA but make distinct contributions to Arabidopsis thaliana flower development. J. Exp. Bot. 2015, 66, 4537-4549. [CrossRef] [PubMed]

26. Klucher, K.M.; Chow, H.; Fischer, R. The AINTEGUMENTA gene of Arabidopsis required for ovule and female gametophyte development is related to the floral homeotic gene APETALA2. Plant Cell Online 1996, 8, 137-153. [CrossRef]

27. Dash, M.; Malladi, A. The AINTEGUMENTA genes, MdANT1 and MdANT2, are associated with the regulation of cell production during fruit growth in apple (Malus $\times$ domestica Borkh.). BMC Plant Biol. 2012, 12, 1-15. [CrossRef] [PubMed]

28. Chialva, C.; Eichler, E.; Grissi, C.; Mu?Oz, C.; Gomez-Talquenca, S.; Martínez-Zapater, J.; Lijavetzky, D. Expression of grapevine AINTEGUMENTA-like genes is associated with variation in ovary and berry size. Plant Mol. Biol. 2016, 91, 67-80. [CrossRef] [PubMed]

29. Jiang, L.; Ma, X.; Zhao, S.; Tang, Y.; Liu, F.; Gu, P.; Fu, Y.; Zhu, Z.; Cai, H.; Sun, C. The APETALA2-like transcription factor SUPERNUMERARY BRACT controls rice seed shattering and seed size. Plant Cell 2019, 31, 17-36. [CrossRef] [PubMed]

30. Zeng, J.K.; Li, X.; Xu, Q.; Chen, J.Y.; Yin, X.R.; Ferguson, I.B.; Chen, K.S. EjAP2-1, an AP2/ERF gene, is a novel regulator of fruit lignification induced by chilling injury, via interaction with EjMYB transcription factors. Plant Biotechnol. J. 2016, 13, 1325-1334. [CrossRef] [PubMed]

31. Chuck, G.; Meeley, R.; Hake, S. Floral meristem initiation and meristem cell fate are regulated by the maize AP2 genes ids1 and sid1. Development 2008, 135, 3013-3019. [CrossRef] [PubMed]

32. Jofuku, K.D.; Boer, B.G.d.; Montagu, M.V.; Okamuro, J.K. Control of Arabidopsis flower and seed development by the homeotic gene APETALA2. Plant Cell 1994, 6, 1211-1225. [CrossRef]

33. Stone, S.L.; Kwong, L.W.; Yee, K.M.; Pelletier, J.; Lepiniec, L.; Fischer, R.L.; Goldberg, R.B.; Harada, J.J. LEAFY COTYLEDON2 encodes a B3 domain transcription factor that induces embryo development. Proc. Natl. Acad. Sci. USA 2001, 98, 11806-11811. [CrossRef] [PubMed]

34. Cheong, J.J.; Choi, Y.D. Methyl jasmonate as a vital substance in plants. Trends Genet. 2003, 19, 409-413. [CrossRef]

35. Krizek, B.A. AINTEGUMENTA and AINTEGUMENTA-like6 act redundantly to regulate arabidopsis floral growth and patterning. Plant Physiol. 2009, 150, 1916-1929. [CrossRef]

36. Rudall, P.J.; Bateman, R.M. Roles of synorganisation, zygomorphy and heterotopy in floral evolution: The gynostemium and labellum of orchids and other lilioid monocots. Biol. Rev. 2010, 77, 403-441. [CrossRef] [PubMed]

37. Hawku, M.D.; Goher, F.; Islam, M.A.; Guo, J.; He, F.; Bai, X.; Yuan, P.; Kang, Z.; Guo, J. TaAP2-15, An AP2/ERF transcription factor, is positively involved in wheat resistance to Puccinia striiformis f. sp. tritici. Int. J. Mol. Sci. 2021, 22, 2080. [CrossRef]

38. Xie, Z.; Nolan, T.M.; Jiang, H.; Yin, Y. AP2/ERF transcription factor regulatory networks in hormone and abiotic stress responses in Arabidopsis. Front. Plant Sci. 2019, 10, 228. [CrossRef] [PubMed] 
39. Ahmeda, S.; Rashid, M.A.R.; Zafar, S.A.; Azhar, M.T.; Waqas, M.; Uzair, M.; Rana, I.A.; Azeem, F.; Chung, G.; Ali, Z.; et al. Genome-wide investigation and expression analysis of APETALA-2 transcription factor subfamily reveals its evolution, expansion and regulatory role in abiotic stress responses in Indica rice (Oryza sativa L. ssp. indica). Genomics 2020, 113, 1029-1043. [CrossRef]

40. Zhao, Y.; Ma, R.; Xu, D.; Bi, H.; Xia, Z.; Peng, H. Genome-wide identification and analysis of the AP2 transcription factor gene family in wheat (Triticum aestivum L.). Front. Plant Sci. 2019, 10, 1286. [CrossRef] [PubMed]

41. Dipp-Álvarez, M.; Cruz-Ramírez, A. A phylogenetic study of the ANT family points to a preANT gene as the ancestor of basal and euANT transcription factors in land plants. Front. Plant Sci. 2019, 10. [CrossRef]

42. Zhao, Y.; Cheng, S.; Song, Y.; Huang, Y.; Zhou, S.; Liu, X.; Zhou, D.X. The interaction between rice ERF3 and WOX11 promotes crown root development by regulating gene expression involved in cytokinin signaling. Plant Cell 2015, 27, 2469-2483. [CrossRef]

43. Diaz-Martin, J.; Almoguera, C.N.; Prieto-Dapena, P.; Espinosa, J.M.; Jordano, J. Functional interaction between two transcription factors involved in the developmental regulation of a small heat stress protein gene promoter. Plant Physiol. 2005, 139, 1483-1494. [CrossRef] [PubMed]

44. Son, G.H.; Wan, J.; Kim, H.J.; Xuan Canh, N.; Chung, W.S.; Hong, J.C.; Stacey, G. Ethylene-responsive element-binding factor 5, ERF5, is involved in chitin-induced innate immunity response. Mol. Plant Microbe Interact. 2012, 25, 48-60. [CrossRef] [PubMed]

45. Moffat, C.S.; Ingle, R.A.; Wathugala, D.L.; Saunders, N.J.; Knight, H.; Knight, M.R. ERF5 and ERF6 play redundant roles as positive regulators of JA/Et-mediated defense against botrytis cinerea in Arabidopsis. PLoS ONE 2012, 7, e35995. [CrossRef]

46. Riechmann, J.L.; Meyerowitz, E.M. The AP2/EREBP family of plant transcription factors. Biol. Chem. 1998, 379, 633-646. [CrossRef]

47. Shukla, R.K.; Raha, S.; Tripathi, V.; Chattopadhyay, D. Expression of CAP2, an APETALA2-family transcription factor from chickpea, enhances growth and tolerance to dehydration and salt stress in transgenic tobacco. Plant Physiol. 2006, 142, 113-123. [CrossRef]

48. Yamaguchi-Shinozaki, K.; Shinozaki, K. Organization of cis-acting regulatory elements in osmotic- and cold-stress-responsive promoters. Trends Plant Sci. 2005, 10, 88-94. [CrossRef] [PubMed]

49. Luo, H.; Chen, S.; Jiang, J.; Teng, N.; Chen, Y.; Chen, F. The AP2-like gene NsAP2 from water lily is involved in floral organogenesis and plant height. J. Plant Physiol. 2012, 169, 992-998. [CrossRef]

50. Shoji, T.; Mishima, M.; Hashimoto, T. Divergent DNA-binding specificities of a group of ETHYLENE RESPONSE FACTOR transcription factors involved in plant defense. Plant Physiol. 2013, 162, 977-990. [CrossRef] [PubMed]

51. Wang, L.; Qin, L.; Liu, W.; Zhang, D.; Wang, Y. A novel ethylene-responsive factor from Tamarix hispida, ThERF1, is a GCC-boxand DRE-motif binding protein that negatively modulates abiotic stress tolerance in Arabidopsis. Physiol. Plant. 2014, 152, 84-97. [CrossRef]

52. Phukan, U.J.; Jeena, G.S.; Tripathi, V.; Shukla, R.K. Regulation of Apetala2/Ethylene response factors in plants. Front. Plant Sci. 2017, 8. [CrossRef]

53. Che, P.; Lall, S.; Nettleton, D.; Howell, S.H. Gene expression programs during shoot, root and callus development in Arabidopsis tissue culture. Plant Biol. 2006, 2006, 282-283. [CrossRef]

54. Du, X.; Fang, T.; Liu, Y.; Huang, L.; Zang, M.; Wang, G.; Liu, Y.; Fu, J. Transcriptome profiling predicts new genes to promote maize callus formation and transformation. Front. Plant Sci. 2019, 10. [CrossRef]

55. Piyatrakul, P.; Putranto, R.-A.; Martin, F.; Rio, M.; Dessailly, F.; Leclercq, J.; Dufayard, J.-F.; Lardet, L.; Montoro, P. Some ethylene biosynthesis and AP2/ERF genes reveal a specific pattern of expression during somatic embryogenesis in Hevea brasiliensis. BMC Plant Biol. 2012, 12, 1-20. [CrossRef]

56. Lee, J.H.; Kim, D.M.; Lee, J.H.; Kim, J.; Bang, J.W.; Kim, W.T.; Pai, H.S. Functional characterization of NtCEF1, an AP2/EREBP-type transcriptional activator highly expressed in tobacco callus. Planta 2005, 222, 211-224. [CrossRef] [PubMed]

57. Iwase, A.; Harashima, H.; Ikeuchi, M.; Rymen, B.; Ohnuma, M.; Komaki, S.; Morohashi, K.; Kurata, T.; Nakata, M.; Ohme-Takagi, M.; et al. WIND1 promotes shoot regeneration through transcriptional activation of ENHANCER OF SHOOT REGENERATION1 in Arabidopsis. Plant Cell 2017, 29, 54-69. [CrossRef] [PubMed]

58. Ye, B.-B.; Shang, G.-D.; Pan, Y.; Xu, Z.-G.; Zhou, C.-M.; Mao, Y.-B.; Bao, N.; Sun, L.; Xu, T.; Wang, J.-W. AP2/ERF transcription factors integrate age and wound signals for root regeneration. Plant Cell 2020, 32, 226-241. [CrossRef] [PubMed]

59. Zhang, K.; Zhao, L.; Yang, X.; Li, M.; Sun, J.; Wang, K.; Li, Y.; Zheng, Y.; Yao, Y.; Li, W. GmRAV1 regulates regeneration of roots and adventitious buds by the cytokinin signaling pathway in Arabidopsis and soybean. Physiol. Plant. 2019, 165, 814-829. [CrossRef] [PubMed]

60. Lee, Y.; Hsu, S.; Yeung, E.C. Orchid protocorm-like bodies are somatic embryos. Am. J. Bot. 2013, 100, 2121-2131. [CrossRef] [PubMed]

61. Teixeira da Silva, J.A.; Cardoso, J.C.; Dobránszki, J.; Zeng, S. Dendrobium micropropagation: A review. Plant Cell Rep. 2015, 34, 671-704. [CrossRef]

62. Ripoll, J.J.; Roeder, A.; Ditta, G.S.; Yanofsky, M.F. A novel role for the floral homeotic gene APETALA2 during Arabidopsis fruit development. Development 2011, 138, 5167-5176. [CrossRef]

63. Samad, A.; Muhammad, S.; Nazaruddin, N.; Fauzi, I.A.; Murad, A.; Zamri, Z.; Ismanizan, I. MicroRNA and transcription factor: Key players in plant regulatory network. Front. Plant Sci. 2017, 8. [CrossRef] [PubMed] 
64. He, C.; Si, C.; Teixeira da Silva, J.A.; Li, M.; Duan, J. Genome-wide identification and classification of MIKC-type MADS-box genes in Streptophyte lineages and expression analyses to reveal their role in seed germination of orchid. BMC Plant Biol. 2019, 19, 1-15. [CrossRef]

65. Yu, H.; Goh, C.J. Molecular genetics of reproductive biology in orchids. Plant Physiol. 2001, 127, 1390-1393. [CrossRef]

66. Cao, Y.; Song, F.; Goodman, R.M.; Zheng, Z. Molecular characterization of four rice genes encoding ethylene-responsive transcriptional factors and their expressions in response to biotic and abiotic stress. J. Plant Physiol. 2006, 163, 1167-1178. [CrossRef] [PubMed]

67. Igarashi, D.; Ishida, S.; Fukazawa, J.; Takahashi, Y. 14-3-3 proteins regulate intracellular localization of the bZIP transcriptional activator RSG. Plant Cell 2001, 13, 2483-2497. [CrossRef] [PubMed]

68. Mishra, S.; Phukan, U.J.; Tripathi, V.; Singh, D.K.; Luqman, S.; Shukla, R.K. PsAP2 an AP2/ERF family transcription factor from Papaver somniferum enhances abiotic and biotic stress tolerance in transgenic tobacco. Plant Mol. Biol. 2015, 89, 173-186. [CrossRef]

69. Chen, J.-Q.; Dong, Y.; Wang, Y.-J.; Liu, Q.; Zhang, J.-S.; Chen, S.-Y. An AP2/EREBP-type transcription-factor gene from rice is cold-inducible and encodes a nuclear-localized protein. Theor. Appl. Genet. 2003, 107, 972-979. [CrossRef] [PubMed]

70. Yu, Y.; Duan, X.; Ding, X.; Chen, C.; Zhu, D.; Yin, K.; Cao, L.; Song, X.; Zhu, P.; Li, Q.; et al. A novel AP2/ERF family transcription factor from Glycine soja, GsERF71, is a DNA binding protein that positively regulates alkaline stress tolerance in Arabidopsis. Plant Mol. Biol. 2017, 94, 509-530. [CrossRef]

71. Thiel, G.; Lietz, M.; Hohl, M. How mammalian transcriptional repressors work. Eur. J. Biochem. 2004, 271, 2855-2862. [CrossRef] [PubMed]

72. Kazan, K. Negative regulation of defence and stress genes by EAR-motif-containing repressors. Trends Plant Sci. 2006, 11, 109-112. [CrossRef]

73. Yaish, M.W.; El-kereamy, A.; Zhu, T.; Beatty, P.H.; Good, A.G.; Bi, Y.-M.; Rothstein, S.J. The APETALA-2-Like transcription factor OsAP2-39 controls key interactions between abscisic acid and gibberellin in rice. PLoS Genet. 2010, 6, e1001098. [CrossRef] [PubMed]

74. Pan, I.C.; Li, C.-W.; Su, R.-C.; Cheng, C.-P.; Lin, C.-S.; Chan, M.-T. Ectopic expression of an EAR motif deletion mutant of SlERF3 enhances tolerance to salt stress and Ralstonia solanacearum in tomato. Planta 2010, 232, 1075-1086. [CrossRef]

75. Drews, G.N.; Bowman, J.L.; Meyerowitz, E.M. Negative regulation of the Arabidopsis homeotic gene AGAMOUS by the APETALA2 product. Cell 1991, 65, 991-1002. [CrossRef]

76. Jofuku, K.D.; Omidyar, P.K.; Gee, Z.; Okamuro, J.K. Control of seed mass and seed yield by the floral homeotic gene APETALA2. Proc. Natl. Acad. Sci. USA 2005, 102, 3117-3122. [CrossRef]

77. Zhou, Y.; Lu, D.; Li, C.; Luo, J.; Zhu, B.-F.; Zhu, J.; Shangguan, Y.; Wang, Z.; Sang, T.; Zhou, B.; et al. Genetic control of seed shattering in rice by the APETALA2 transcription factor SHATTERING ABORTION1. Plant Cell 2012, 24, 1034-1048. [CrossRef] [PubMed]

78. Liu, L.S.; White, M.J.; MacRae, T.H. Transcription factors and their genes in higher plants functional domains, evolution and regulation. Eur. J. Biochem. 1999, 262, 247-257. [CrossRef] [PubMed]

79. Murashige, T.; Skoog, F. A revised medium for rapid growth and bio assays with tobacco tissue cultures. Physiol. Plant. 1962, 15, 473-497. [CrossRef]

80. He, C.; Zeng, S.; Teixeira da Silva, J.A.; Yu, Z.; Tan, J.; Duan, J. Molecular cloning and functional analysis of the phosphomannomutase (PMM) gene from Dendrobium officinale and evidence for the involvement of an abiotic stress response during germination. Protoplasma 2017, 254, 1693-1704. [CrossRef]

81. Kumar, S.; Stecher, G.; Tamura, K. MEGA7: Molecular Evolutionary Genetics Analysis Version 7.0 for bigger datasets. Mol. Biol. Evol. 2016, 33, 1870-1874. [CrossRef]

82. Larkin, M.A.; Blackshields, G.; Brown, N.P.; Chenna, R.; McGettigan, P.A.; McWilliam, H.; Valentin, F.; Wallace, I.M.; Wilm, A.; Lopez, R.; et al. Clustal W and clustal X version 2.0. Bioinformatics 2007, 23, 2947-2948. [CrossRef]

83. Saitou, N.; Nei, M. The neighbor-joining method - a new method for reconstructing phylogenetic trees. Mol. Biol. Evol. 1987, 4, 406-425. [CrossRef] [PubMed]

84. Lu, S.; Wang, J.; Chitsaz, F.; Derbyshire, M.K.; Geer, R.C.; Gonzales, N.R.; Gwadz, M.; Hurwitz, D.I.; Marchler, G.H.; Song, J.S.; et al CDD/SPARCLE: The conserved domain database in 2020. Nucleic Acids Res. 2020, 48, D265-D268. [CrossRef] [PubMed]

85. Chen, C.; Chen, H.; Zhang, Y.; Thomas, H.R.; Frank, M.H.; He, Y.; Xia, R. TBtools: An integrative toolkit developed for interactive analyses of big biological data. Mol. Plant 2020, 13, 1194-1202. [CrossRef] [PubMed]

86. Szklarczyk, D.; Gable, A.L.; Lyon, D.; Junge, A.; Wyder, S.; Huerta-Cepas, J.; Simonovic, M.; Doncheva, N.T.; Morris, J.H.; Bork, P.; et al. STRING v11: Protein-protein association networks with increased coverage, supporting functional discovery in genome-wide experimental datasets. Nucleic Acids Res. 2019, 47, D607-D613. [CrossRef] [PubMed]

87. He, C.; Zhang, J.; Liu, X.; Zeng, S.; Wu, K.; Yu, Z.; Wang, X.; Teixeira da Silva, J.A.; Lin, Z.; Duan, J. Identification of genes involved in biosynthesis of mannan polysaccharides in Dendrobium officinale by RNA-seq analysis. Plant Mol. Biol. 2015, 88, $219-231$. [CrossRef] [PubMed]

88. Livak, K.J.; Schmittgen, T.D. Analysis of relative gene expression data using real-time quantitative PCR and the $2^{-\Delta \Delta C T}$ method. Methods 2001, 25, 402-408. [CrossRef]

89. Citovsky, V.; Lee, L.-Y.; Vyas, S.; Glick, E.; Chen, M.-H.; Vainstein, A.; Gafni, Y.; Gelvin, S.B.; Tzfira, T. Subcellular localization of interacting proteins by bimolecular fluorescence complementation in planta. J. Mol. Biol. 2006, 362, 1120-1131. [CrossRef] 
90. Yoo, S.-D.; Cho, Y.-H.; Sheen, J. Arabidopsis mesophyll protoplasts: A versatile cell system for transient gene expression analysis. Nat. Protoc. 2007, 2, 1565-1572. [CrossRef] [PubMed]

91. Han, Y.-C.; Kuang, J.-F.; Chen, J.-Y.; Liu, X.-C.; Xiao, Y.-Y.; Fu, C.-C.; Wang, J.-N.; Wu, K.-Q.; Lu, W.-J. Banana transcription factor MaERF11 recruits histone deacetylase MaHDA1 and Represses the expression of MaACO1 and Expansins during fruit ripening. Plant Physiol. 2016, 171, 1070-1084. [CrossRef] [PubMed] 